\title{
An educational methodology based on the work of students
}

\author{
Sylvia da Rosa \\ Instituto Universitario Autónomo del Sur \\ Montevideo, Uruguay \\ darosa@fing.edu.uy \\ and \\ Federico Gómez Frois \\ Instituto Universitario Autónomo del Sur \\ Montevideo, Uruguay \\ Federico.Gomez.Frois@universitario.edu.uy
}

\begin{abstract}
In the year 2006 the "Instituto Universitario Autónomo del Sur" decided to introduce a modification in the curricula of its Computer Science careers. Such modification was based on the guidelines of the Bologna process, particularly on the adoption of a credit system similar to the ECTS (European Credit Transfer System). The authors of this article saw this institutional decision as an opportunity to enhance an educational reform. The reform would modernize undergraduate programs, by establishing that students would have a main role in the educational process. This goal may only be achieved by a transformation of traditional teaching practices. Therefore, teachers, students and the institution have to undergo a process of deliberation and creation. In this article, the authors describe the process applied to the teaching staff, and the application of an innovative methodology developed for the first course of Programming. Extracts of interviews to students are also included.
\end{abstract}

Keywords: Bologna process, credit system, epistemology.

\section{INTRODUCTION}

The "Instituto Universitario Autónomo del Sur" (IUAS) is a Uruguayan educational private institution [13], that was acknowledged by the Ministry of Education and Culture as a University School in 1996. Since then, the Institute trains University professionals in Computer Science.

The first curriculum was created in 1996 and was updated in several occasions until 2006. In that year, the institution considered facing the challenge of introducing a modification in the curriculum, taking into account not only the thematic content but also education and apprenticeship methodologies [1].

For the reform, the authors were inspired by some guidelines of the Bologna process developed in Europe with the purpose of establishing a quality educational system in 2010. This could become a European model of competitive capability at an international level, called European Higher Education Area (EHEA) [10]. Although some countries are reluctant to implement this change, it is widely well-known that the process proposes the revision of the traditional teaching-learning practices and suggests ways to modify these practices. These suggestions are based on solid epistemological and pedagogical principles, including the responsible integration of the possibilities that technological development provides.

For a successful change, it is essential to adopt a credit system: The European Credit Transfer System (ECTS) [11]. The adoption of this credit system has, among other things, a major consequence: it represents a fundamental change of the educational paradigm concept, expressed by the following definition of credit:

A credit is a unit to measure the student's dedication, which includes all of his/her activities, that is to say: assistance to theoretical and practical classes, hours devoted to studying, carrying out seminars, projects or other type of works. By assigning credits to each subject, it is possible to estimate the number of work hours devoted by the student to acquire the corresponding capabilities and skills. 
This definition implies deep transformations in the roles of both students and teachers since, commonly, traditional practices are based on teachers' explanations and lectures, while the activities of students are considered mostly during evaluations. Since the curriculum created in the IUAS in 2006 adopts a credit system similar to the ECTS, the authors of this article saw in the institutional decision an opportunity to forge an educational methodology based on the Bologna process, aimed at transforming traditional and deep-rooted teaching practices. To put this idea into practice, the teaching staff was trained in the new plan; it was designed as workshops and implemented in the second semester of 2007.

The theoretical bases for the convenience of the change of paradigm are the postulates of the epistemological theory "Genetic Epistemology" by Jean Piaget [8]. This provides satisfactory explanations on the construction of knowledge and has been the foundation of modern pedagogical theories, such as the Mental Models Theory and Constructivism $[2,5,9]$. One of the main theoretical principles of Piaget's theory is that the source of instrumental knowledge is the interaction between the subject and the object, governed by the general law of cognition [7]. This explains how instrumental knowledge may be transformed in conceptual knowledge by the individual. The major instrument of the entire process is called reflective abstraction and the factor that plays an essential role as driving force of the process is the search of reasons and the inherent necessity. Piaget points out that the construction of the subject is not satisfactory, in the final analysis, unless it acquires intrinsic necessity, through explicit reasons [8]. Based on these ideas, the educational methodology proposed in this work consists in taking into account the knowledge constructed by students while solving instances of problems. Through appropriate questions, the students are encouraged to express their solutions in common language and to describe what they did and why they succeeded (or failed). The formalization of the concepts is introduced in a later stage. This is one of the differences of this methodology compared with traditional ones. An approximation of this methodology is described in section 3 .

This article is divided into sections which include the following information: Section 2: The activity of the workshops where the work with the teaching staff took place; Section 3: The list of experiences of the Programming Courses; Section 4: The extracts of the interviews to students; Section 5: The analysis of the impact of the complete work on teachers, students and the institution; Section 6: The conclusions drawn and the guidelines for future work. Finally, references are included.

\section{Educational InNOvation Workshops}

The workshops' activity (called "educational innovation workshops") was planned and organized by the authors of this article (with the corresponding institutional support). The expectations were to achieve two fundamental objectives: First, to disclose the details of the modification in the curriculum to the rest of the teaching staff, especially regarding the Bologna process and the credit system; second, to ponder over the transformations for the educational methodology expected by the authors.

Five workshops were carried out on Saturdays of the second semester of 2007. They included a total of fifteen hours of face-to-face sessions for the teaching staff and workload. This workload was additional to the workshops and was not established beforehand, for it depended on each member of the teaching staff. The teachers responsible for each subject of every career participated in workshops, including teachers from Programming, Software Engineering, Mathematics, Databases, Theory of Computer Science, Operating Systems, and Computer Architecture. The purpose was to have these members of the teaching staff acting as transmitters and support for the other colleagues. During these hours of contact, the aspects of the new curriculum which imply pedagogical innovations were discussed, and the traditional practices were evaluated. To start the evaluation, some questions were analyzed, such as: How is it taught at universities? How do students learn in these institutions? Which are the major pedagogical orientations? Do you know of any alternatives? Could you please assess the quality of the current educational system? Which is your opinion about the use of ICT on education? In short, why should it be changed? Which are the ways to achieve an effective change?

With the analysis of the answers, it became clear that traditional methodology prevails: The teacher introduces the course topics and the student listens, takes notes and eventually asks to the teacher questions regarding his/her explanations. All the teaching staff acknowledges the learning deficiencies that occur with this methodology. However, most of them recommended overcoming these deficiencies by providing better explanations, by increasing the number of tutorial classes, as well as practical and/or theoretical classes. In terms of students, it was pointed out that they start University poorly qualified and that they do not study as much as they used to do.

In the workshops, the implications of the adoption of a credit system from a pedagogical point of view were discussed. Some of the questions posed were: What does it mean to measure the student's dedication, and what difference does it make in the work of teachers. 
There was an introduction to a methodology of initial concepts, based on principles from Piaget's theory, as well as to specific examples describing how the interaction of the students with instances of a problem can help them to elaborate the concepts involved and to formalize these concepts [3].

In this interaction, the student should be able to express in his/her native language (in this case, Spanish) what he/she understands about the problem and its solution. The teacher encourages and guides this interaction. The conclusion of the workshops was an evaluation of the activity, by gathering the viewpoints of the participants. There was also a synthesis and refining of some of the topics discussed. Then, as a result of the activity, it was agreed on that every teacher had to elaborate a specific document for his/her subject, contemplating eventual changes to be implemented to teach and learn the subject. During the year 2008, the teachers of programming subjects (Programming 1, 2, 3 and 4), designed and applied an approach of the suggested methodology. This is illustrated in the next section, which includes the description of the most important aspects in the case of Programming 1.

\section{The Proposal of the Programming 1 Teaching Staff}

The Programming 1 course is an initial course of programming for freshmen, which introduces the $\mathrm{C}++$ language. As a first approach to the methodology, the teaching staff elaborated, for each topic of the course, a list of questions (a guideline) for the student to answer after having read the available material on the Web and before assisting to class. In class, the answers were presented and discussed by the students, with the guide and intervention of the teacher if necessary. Thus, the student's individual work was complemented with a discussion where other students were involved. This allowed constructing solid knowledge following epistemological principles.

There follows a section of the list of questions from the guide elaborated to introduce the topic "Arrays". The reasons for asking these questions are briefly explained.

Table 1: Questions 1 - 7

\begin{tabular}{l}
\hline Question \\
\hline 1. Explain in your own words what an array is. \\
\hline 2. Give a real example of an array. \\
\hline 3. Is an array the same thing as a set? \\
\hline 4. In which situations would you use an array in a program? \\
\hline 5. May values "a", $3,2.5$ be stored in a single array? \\
\hline 6. Which is the start value of the indexes (or positions) of an array in $\mathrm{C}++$ ? \\
\hline 7. Draw an array with 8 integers and its corresponding indexes. \\
\hline
\end{tabular}

One of the pedagogical implications of the epistemological principles, on which our proposal is based, is to consider that formalization in the native language is the first step in the elaboration of concepts. In this way, the student shall be able to concentrate on the object he/she should know (in this case the array) given that he/she uses a familiar language to communicate. Formalization in $\mathrm{C}++$ is dialectically introduced while the student progresses in the elaboration of the concept "array", since C++ formalization constitutes another learning object for the student.

Table 2: Questions 8-9

\begin{tabular}{l} 
Question \\
\hline 8. How is a type array in $\mathrm{C}++$ defined? Indicate the generic syntax and explain the \\
meaning of each component of the definition. \\
9. Explain in your own words what do the following instructions do. \\
int arre[3]; arre[0] $=27$; printf ("\% $\%$ ", arre[0]); scanf (“\%d", \&arre[1]);
\end{tabular}

The student is encouraged to find solutions to problems in which the manipulated objects are the arrays. The generalization of specific values to abstract variables is gradually introduced.

Table 3: Questions $10-11$

\begin{tabular}{l} 
Question \\
\hline 10. If I wanted to store the following three values in an array: 5,7 and 9 , how many \\
arrays of three elements may I form with these values? Draw all the possible arrays \\
that may be formed with these three values. \\
11. Generalizing the previous question, if I had N possible values, how many N arrays \\
may I form with these N values?
\end{tabular}


Once the concept of array and its $\mathrm{C}++$ formalization are introduced, the work is with the operations that may be carried out with said objects, following pedagogical guidelines, by which the objects and their operations constitute a single learning object. With the following questions, the students -while interacting with arrays and using the basic operations (for instance the assignment)- should be able to find out the operations mentioned below by themselves with no previous explanation of the teacher.

Table 4: Questions 13 - 15

Question
13. We are going to exercise the charge operation of an array. Define in C++ an array
of $\mathrm{N}$ integer values ( $\mathrm{N}$ is a symbolic constant). Then, write in C++ a program fragment
that charges the array's cells with values read from the keyboard. Define all the
necessary auxiliary variables.
14. Now, we are going to exercise the selection and rewriting operations. Write
another program fragment that reads a value and a position from the keyboard. The
program should store that value in that array's position (thus replacing the previously
stored value) and then either show on screen the new value stored or issue an error
message to the user if that array's position does not exist.
15. Now, we are going to exercise the verification of equality. Given two arrays of $\mathrm{N}$
cells each (presumably already charged with values), write another program fragment
which establishes if these arrays are equal (that is to say, if they have the same values
stored in the same positions). Issue a message to the user with the result.

Finally, the student is encouraged to analyze his/her own solutions and to explain why these solutions were successful, associating the concept to other concepts (control structures, in this case). To search for the reasons of a successful solution is one of most powerful mechanisms in the knowledge construction process [8].

Table 5: Question 16

Question
16. Name the control structures used in the last three questions and explain briefly the
reasons for choosing them for each situation.

It is clear that the proposed methodology takes very much into account the student's work in the elaboration of the concept and its formalization, as opposed to the traditional presentation, in which students work on the practical exercises based on the formalization introduced by the teacher. By the traditional methodology, the student has no connection with his/her eventual experience in the topic and has no interaction in situations with the problem. Please refer to [13] for the material of Programming 1.

\section{Extracts From the INTERVIEWS}

Seven volunteer students were interviewed (out of a total of 70), during approximately 30 minutes. The purpose of the interviews was to gather information about the students' assessment of the impact of the methodology over their way of working. This information would constitute the grounds for the application of the methodology in the same subject and in other subjects as well. The information from interviews would also help to improve the methodology.

A list of questions was elaborated as basis. During the interviews, the wording of questions may vary or other new questions may be added, depending on the student responses. Every interview was recorded and transcribed, for its further analysis. There follow extracts from the interviews. For their complete transcription and the list of questions please refer to [13]. To order the description, the students' responses to each question are numbered, and comments are added. In italic the content of the students' responses considered most important were hightlighted. The text between straight brackets is added by the authors. The answers appear in the Spanish variation used by students in Uruguay.

The first question (What is your opinion about the new teaching-learning methodology that we are applying?) is relevant to place the student in the interview's context. Because usually, the student's attention is not on the fundamental change, which implies that they must study the topics before coming to class, as in fact was proved by their responses. The purpose of this question is to focus the students' attention on this aspect of their work that is the authors are interested in.

All the students admitted having used the questions' guides, and that they turned out to be useful in their study work. The question Why do you consider the methodology helped you in the learning process? is a key question by which it is possible to know how valuable for the students are their own efforts in the learning process. The 
students' responses prove that they believe their own efforts are valuable. The following are some of their explanations.

Student 1: The student participates more in class and I think that he gets more involved. You can check your own notes, I think it is more personalized; coming to class rather prepared maybe helps you to reaffirm the concepts or understand others. It helps, whether you like it or not.

Student 2: What I noticed is that what helps the most is that you don't go to class without having read anything, because usually, if you don't have to answer questions and your classes are on Mondays, you probably won't read the texts on Sunday. For that I consider it helps, because even though you can't answer all of the questions or you still have some doubts, you don't come to class without having a clue, expecting the teacher to do all the work for you.

Student 3: This methodology is useful; because you must sit down to see which are the specific issues of this subject. Sometimes, you download the material but don't actually read it, so you miss the main points; with this sheet, you see the main points, because it guides you and you come [to class] with different ideas in your head ... Having access to the material on the website and having the questions' guide is very good.

Student 4: Oh yes, the teacher gives us a letter [the student is referring to the questions' list] of what you have to work on and that's good, because you must study the material -obviously there'll be doubts- so, it helps because when the teacher is explaining something, we already know what he is talking about...

Regarding the questions referred to whether the participation in class, both in the presentation of the answers and in the general discussion, was fruitful or not, we gathered the following extracts:

Student 1: Yes, I believe that that's when the topic, so to speak, becomes clear, right? For example, sometimes someone answers the question in a wrong or imprecise way... In general, it is during these group discussions between the teacher and the students, when things become clearer, so to speak.

Student 2: Yes, of course! All questions were answered, from the first to the last question and, well, you stepped to the front and had to explain. To stand facing the class is a challenge, so is to write on the board and, even more challenging is to look at them yourself [referring to his own explanations]. After finishing the concept and reading it from the board I believe you internalize a lot.

Student 3: Yes, I believe it is useful [referring to the discussion in class] because we all come with work done, with the topics ready, and then we can see the differences, with the teacher's intervention. From my point of view, a lot of doubts and confusing concepts become clear; you can learn a lot.

Student 4: Some questions were easily understood, others only partially, that's why answering them in class was not easy. However, when the classmates that had understood the questions answered them, in the discussion and the presentation, it helped me understand.

Student 5: Yes, because the input of every classmate is enriching as it gives a different perspective that you hadn't contemplated or that you thought wouldn't be possible. It is good to know why it is possible even when you thought it was not.

The following question (We know there are students who dislike the methodology, what do you think about it?) was included because none of the students who were reluctant to the application of the methodology volunteered for the interviews. There follow the opinions gathered:

Student 1: Yes, the thing is that it demands studying at home. I guess that is why the theoretical part is published since day one. It is important you do it from the very beginning; you have to be one class ahead of the teacher to understand what he is talking about. But if you don't keep up this pace, obviously it won't work.

Student 2: In my case, I prefer having a guide, unless the teacher is very good. Then, I know what to study, what I should have learnt in class, even if I don't understand what the teacher explained, I can still study it by myself.

Student 3: After a class, you should sit down and study; you only learn if you study. So, this student [reluctant to the methodology] would have to work double... But if you were already in class with some guidance, things are different. 
Student 4: I know that some classmates don't enjoy being at home working on the theoretical material, but you should read it, so that when the teacher explains, you already have an idea of the topic. Some partners are lazy and prefer the teacher explaining everything to them. Not me, I think it is good, I agree with the methodology but in some topics, the theoretical material should cover more...

The last comment is related to the fact that in these interviews there were also questions about the practical and theoretical materials, the mandatory tasks, the programming language used, the generic attributes and the continuity of the different subjects. These questions are not included in the present article but are included in the full list of questions [13].

All students responded affirmatively to the question: Would you recommend the extension of this methodology to other subjects? In some cases, the students described the difficulties they have in other subjects in which the traditional methodology is applied.

\section{Analysis}

One of the main goals of the work described in this paper is to make actors of the educational process aware of the pedagogical changes that adopting a credit system implies. In this section, the authors analyze the impact that the attempt to achieve this goal has on the three main actors: the teachers, the students and the institution.

In our country, some institutions adopted a credit system based on the Bologna process, but none of them faced the discussion considering the impact that this adoption has on the educational methodology. In this sense, the support of the institution IUAS, which allowed and enhanced the organization and practice not only of the workshops but also of the innovations that were introduced in each programming course, was determinant for the success of the proposal. Moreover, the institution recommends following this methodology and encourages extending its application.

The fact that the teacher staff of programming courses developed the approach to the methodology described in section 3 proves the impact of the workshop activities on the teachers' attitude. For some teachers the methodological approach may seem obvious, (one of the workshop participants mentioned: "we are only asking the students to study"). However, the analysis of the experience in programming courses shows that there is an important difference between "asking the students to study" and elaborating lists of questions to guide them on every topic with later class discussions and presentations aligned to help them in the construction of knowledge. In this task the teacher's role changes and to implement it successfully requires practice learning. The interaction between the student's participation and the teacher's guide is dialectic: the latter is constantly nurturing himself/herself from the former. Therefore, the teacher shall find out which are the obstacles that exist in the construction of knowledge, and shall be able to suggest new problems to overcome these obstacles.

The purpose of the interviews was to gather students' opinions. The authors believe the percentage of students that participated is irrelevant. The strength of this work lays in its connection with educational related disciplines as theoretical argumentation and the evidence provided of their effectiveness, as pointed out in [4].

From the interviews it is clearly seen that the students acknowledge the suitability of the methodology in terms of the impact on their working procedures, as proved by their answers. Expressions such as: "...when the teacher is explaining something, we already know what he is talking about....", "...you have to be one class ahead of the teacher to understand what he is talking about", “...we all come with work done, with the topics ready ...”, "...However, when the classmates that had understood the questions answered them, in the discussion and the presentation, it helped me understand." shows that the students evaluate positively, not only the individual work they do before class but also the joint work done in class. From their opinions it is also clear that they do not think that students who disagree with the application of the methodology do it for serious reasons: "... Some partners are lazy and prefer the teacher explaining everything to them".

From a different viewpoint, the student realizes that his/her learning process is mainly his/her responsibility (neither the teacher's nor the institution's). This is a fundamental educational motivation. The kind of transformation in the roles of teachers and students pursued with this work cannot be achieved immediately; on the contrary, changes in educational systems usually take time. In Europe, although the change is confronted as a great challenge with important pedagogical implications $[12,6]$ in some Universities, in others the adoption of the credit system is only a change of rating.

No significant change in the students' performance was expected. Although there is no detailed analysis of the quantitative data of the course's results, it is important to confirm that the results are not worse than results of previous years. With a preliminary glance at the results it is already possible to estimate that despite the level of 
approval has not increased significantly, the quality of the evaluated works improved, both in the approved and failed works.

One aspect worth considering is the evaluation methods. In this aspect there is an inconsistency that needs to be overcome: While the work applies a methodology that is different from the traditional, students are evaluated according to traditional methods. It is the authors' concern to study the matter of evaluation methods to overcome this inconsistency and to be capable of measuring the impact of the proposal under the concepts' learning perspective.

Finally, it should be noted that the interviews show valuable information (referred to guides, materials, etc.) that enhances improvement of the methodology. This is not included in the present article.

\section{Conclusions and Further Work}

The educational innovation workshops were very satisfactory and productive as unveiled by the experience of the Programming teachers in the workshops. Most of the workshop's participants wrote reports, with ideas of the methodology's application in different subjects. The work aimed at the institution's teachers must be persistent and continuous for an effective transformation of the traditional practices. To do so, it is essential to receive the institutional support provided by IUAS. The year 2009 started with two events to release the methodology among all the institution's teachers. Extracts from the students' interviews were presented there.

Likewise, the authors are working in two relevant aspects. On one side, the investigation of possible alternative evaluation methods (pair evaluation, collaborative evaluation, etc.), which implies, among other, an analysis comparing the quantitative data of the results of previous editions of courses with the quantitative data of current editions. On the other hand, the methodology designed and applied by the Programming teaching staff provides students with the formalized theoretical and practical material. One of the improvements is using the student's work in the elaboration of the theoretical material as well as in the practical problems suggested, at least for some of the topics. Exchange with students provides information about learning aspects (preconceived notions, different obstacles) which are important to advance in that sense.

\section{References}

[1] Al-Mahmood, Reem. Gruba Paul. Approaches to the Implementation of Generic Graduate Attributes in Australian ICT Undergraduate Education, Computer Science Education, volume 17, number 3. Sept. 2007.

[2] Carlisle, E. George. Experiences with Novices: The Importance of Graphical Representations in Supporting Mental Models, in A.F.Blackwell and E.Bilotta (Eds.) Proceedings of the Twelth Annual Meeting of the Psychology of Programming Interest Group pp 33-44. 2000.

[3] da Rosa, Sylvia. The Learning of Recursive Algorithms and their Functional Formalization. Doctoral thesis. December 2005. www.fing.edu.uy/ darosa/\#work

[4] Holmboe, Christian. Mclver, Linda. Carlisle, E. George: Research Agenda for Computer Science Education, in G. Kadoda (Ed). Proc. PPIG 13 pp 207-223. 2001.

[5] Mordechai, Ben-Ari. Constructivism in Computer Science Education. Journal of Computers in Mathematics and Science Teaching, volume 20, number 1. 2001.

[6] Pastor, Carmen A. La viabilidad de las propuestas metodológicas para la aplicación del crédito europeo por parte del profesorado de las Universidades españolas, vinculadas a la utilización de las Tics en la docencia y la investigación. 2004. Número de referencia para Internet: EA2004-0042.

[7] Piaget, Jean. La Prise de Conscience. Presses Universitaires de France. 1964

[8] Piaget, Jean. Garcia, Rolando. Psychogenesis and the History of Sciences. Columbia University Press, New York. 1980.

[9] Apos theory: A Constructivist Theory of How Learning a Mathematical Concept Might Take Place. http://www3.hi.is/ joner/eaps/wh_apos.htm

[10] Conferencia de Rectores de las Universidades Españolas (Espacio Europeo). http://www.crue.org/espacioeuropeo

[11] European Credit Transfer System. http://www.ects.es/es/ects-1

[12] Innovación Educativa y Calidad en UPM (EEES). http://www.upm.es/innovacion/cd/index4.htm

[13] IUAS: Espacio de Innovación Educativa. http://www.autonomo.edu.uy/moodle (the user name to log in is: guestuser and the password is: invited) 